\title{
電磁界解析による超電導発電機の三相突発短絡時 の過渡現象近似解析
}

$\begin{array}{llllll}\text { 正員新 谷 敏 } & \text { 朗 } & \text { (福山大) } \\ \text { 正員 仁 } & \text { 田 } & \text { 旦 } & \text { (京都大) } \\ \text { 正員 岡 } \text { 田 } & \text { 隆 夫 } & \text { (京都大) }\end{array}$

\section{1.まえがき}

超電势発電機は従来形の同期発電機に比へて理々 の特長をすつので，世界各国で試作，研究されてい $ろ^{(1)(2)}$ 。超電導発電機は通常二重のダンパ円筒を備え

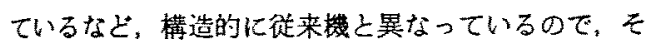
の電気特性を十分に把据するととが必要である。特

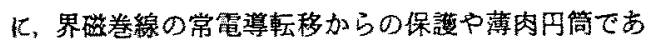
ろタ゚ンパの機峨的強度の点で，系統事故などの恧度時 の特性の把握が必要である。

良来加超電導発電機の電気特性の解析が行われて いるが、その方法は大別して二つの考え方で行われて きた。一つは，徒来形の発電機の等洒回路を抗張した

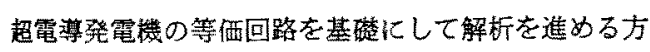
法である。すなわち、ダンバ巻線を值軸，横軸各々一 つの集中定数回路と仮定するものて，その等価回路を 基にして電機子電流，界磁電流などの解所解加得られ る(3)。この方㕕では，ダンパ円筒を集中定数回路とす る仮定に対して明確な議諭がて，またダンパ電流を 正確に过求められない。6う一つの法は，超電導発 電譏の構造モデルを作成し，電磁界解析によってその 電気特性を解折しようというものである。この方法て は，超電導発電㙨のダンパは二重の導電性円筒である ので,オペレーショナルインピーダンスが変形ベッセ

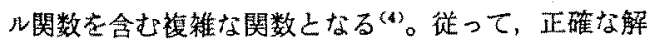
を得るためには数值解析 ${ }^{(5)}$ によらなければならない。

Approximate Transient Analysis of Superconducting Generator at Three-Phase Sudden Short Circuit Based on Electro-Magnetic Analysis. By Toshiro Shintani. Member (Facults of Engineering. Fukuyama University). Tanzo Nitta, Member \& Takao Okada, Member Faculty of Engineering, Kyoto University).

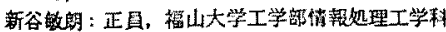

E田旦三：正是，新都大学工学副氞気工学教室

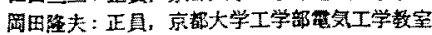

著者らは，発電機の構造パラメータとその電気特性 の関係を把捏するために，前諭文(4)において電磁界 解析を基にオペレーショナルインピーダンスの有理閣 数近仪式学いた。本論文では，その結果を用いて三 相乫発短絡時の電機子電流七界磁電流の解析解交近仪

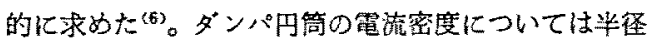
方向，周方向の分布を考慮した解所解を同檬に求め $た^{(6)}$ 。更に，1GVA 級の超笔導軓電機について，数 值逆ラプラス変換による解上比較して解析解か十分な 精度で寒用できるしとを示した。るして，解析解によ り構造パラメータと解の関係を考察した。

\section{2. 解析モデル}

超電導発電機は一般的に空心口回転界磁形で，界磁 巻線を熱的，磁気的に遮へいするたかの低温ダンパ と，機械的振動抑制のための常温ダンパの二重の導電 性ダンパ円筒をもつ。このような超電等発電機に対す

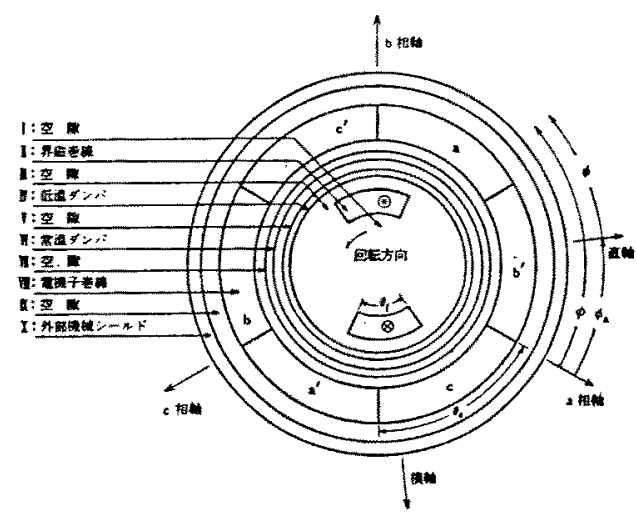

図 1 超電導発電機の解析たデル

Fig. 1. Model of superconducting generator for analysis. 
る二次元解析モデルを図 1 亿示す。同図で領域 II $\left(R_{f i}\right.$ $\left.\leqq r \leqq R_{f o}\right)$ ， 䜣 $\left(R_{i a} \leqq r \leqq R_{a o}\right)$ 方各々界磁，霞機子卷 線部である。領域 $\mathrm{IV}\left(R_{1 i} \leqq r \leqq R_{10}\right), \mathrm{VI}\left(R_{2 i} \leqq r \leqq R_{20}\right)$

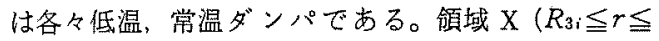
$R_{3}$ ） は外部機械シールドである。周方向の角度を図 1 に示すように，回転子上（创域 $I \sim \mathrm{V}$ ) では $\phi$, 固 定子上（䫁域揵〜X) では $\phi$ する。本論文で用いる 記号は付録にまとめて示した。

\section{3. 三相突発短絡時の過渡解析}

$\langle 3.1\rangle$ 電機子電流の過渡変化 同期発電機に极 けるパークの基本式をラプラス变換形で書くと

$$
\left.\begin{array}{l}
V_{d}(s)=-s \Psi_{d}(s)-\omega_{0} \Psi_{q}(s)-r_{a} I_{d}(s) \\
V_{q}(s)=-s \Psi_{q}(s)+\omega_{0} \Psi_{d}(s)-r_{a} I_{q}(s)
\end{array}\right\}
$$

である。三相突発短絡故障を考えるので零相分は省略 した。角周波数は同期角周波数 $\omega_{0}$ で一定上する。

$\Psi_{d}(s), \Psi_{q}(s)$ は次式で与えられる。

$$
\left.\begin{array}{l}
\Psi_{d}(s)=\left\{X_{d}(s) I_{d}(s)+G(s) E_{f d}(s)\right\} / \omega_{0} \\
\Psi_{q}(s)=X_{q}(s) I_{q}(s) / \omega_{0}
\end{array}\right\}
$$

上式で $X_{d}(s), X_{q}(s)$ がオペレーショナルインピーダ ンスである。また， $E_{f d}(s)$ は界磁電圧， $G(s) / \omega_{0}$ 琾 磁電压之直軸巻線銧交磁束数 $\Psi_{d}(s)$ との伝達関数であ る。発電機端子で三相突発短絡が生じた場合は，重ね 合せの理により,

$$
\begin{aligned}
& V_{d}(s)=V_{L} \sin \delta / s \\
& V_{q}(s)=-V_{L} \cos \delta / s \\
& E_{f^{\prime} d}(s)=0
\end{aligned}
$$

ここで, $V_{L}:$ 発電機端子の短絡前の線間電

王, $\delta$ : 端子電王と内部誘導起電力の位相差 である ${ }^{(7)} 。(2),(3)$ 式を(1)式に代入すると, 電機 子䉓流の変化分のラプラス変換は次式となる。

$$
\left.\begin{array}{rl}
I_{d}(s)= & -V_{L}\left\{\left\{r_{a}+s X_{q}(s) / \omega_{0}\right\} \sin \delta\right. \\
& \left.+X_{q}(s) \cos \delta\right] /\{s \Delta(s)\} \\
I_{q}(s)= & -V_{L}\left[-\left\{r_{a}+s X_{d}(s) / \omega_{0}\right\} \cos \delta\right. \\
& \left.+X_{d}(s) \sin \delta\right) /\{s \Delta(s)\}
\end{array}\right\}
$$

ただし， $\Delta(s)$ は次式で与えられる。

$$
\begin{aligned}
\Delta(s)= & \left(s^{2} / \omega_{0}^{2}+1\right) X_{d}(s) X_{q}(s) \\
& +s r_{\alpha}\left\{X_{d}(s)+X_{q}(s)\right\} / \omega_{0}+r_{a}{ }^{2} \ldots
\end{aligned}
$$

二次元解析によれば， $X_{d}(s) ， X_{q}(s)$ の理諭式は変形 ベッセル関数を含む複雑な関数なので(4)，(4)式の逆 ラプラス変換を解析的に笑行するのは困嚾である。徉 って，正確な解を得ようとすれば数值解析によるとと
になる。本論文では，超電賏発電機の過渡特性之構造 パラメータの関係を簡便に把握するために，数值解析 によらず $X_{d}(s), X_{q}(s)$ が次式のように有理関数で近 似できること〔4)を用いて解析的に解くことを考える。

$$
\begin{aligned}
& X_{d}(s)=X_{d} \frac{\left(1+s T_{d}^{\prime}\right)\left(1+s T_{d}^{\prime \prime}\right)\left(1+s T_{q}{ }^{\prime \prime \prime}\right)}{\left(1+s T_{d o^{\prime}}\right)\left(1+s T_{q o}{ }^{\prime \prime}\right)\left(1+s T_{q o} o^{\prime \prime}\right)} \\
& X_{q}(s)=X_{d} \frac{\left(1+s T_{q}^{\prime \prime}\right)\left(1+s T_{q}^{\prime \prime \prime}\right)}{\left(1+s T_{q o}{ }^{\prime \prime}\right)\left(1+s T_{q o} o^{\prime \prime \prime}\right)}
\end{aligned}
$$

上式で $X_{d}$ は同期りアクタンス， $T_{d}^{\prime} \sim T_{q}{ }^{\prime \prime \prime}$ は時定数 であり，二次元解析に上れば超電導発電機の構造パラ メータの簡単な関数で表される(4)。

$X_{d}(s), X_{q}(s)$ は分母, 分子と击にsについて各三, 二次なので(4)式の分母は $s$ の八次式となる。徒了 て，因数分解に上って(4)式の根を求的ることは代数 的には不可能である。そこで，(6)式中の時定数に，

$$
\begin{aligned}
& T_{d o^{\prime}}>T_{d^{\prime}} \gg T_{q o^{\prime \prime}}>T_{d^{\prime \prime}}>T_{q}{ }^{\prime \prime} \\
& \gg T_{q o}{ }^{\prime \prime \prime}>T_{q}{ }^{\prime \prime} \gg 1 / \omega_{0} \ldots \ldots \ldots . . .
\end{aligned}
$$

の関係があるとと(7) 考慮する。すなわち， $X_{d}(s)$,

\begin{tabular}{|c|c|c|c|c|}
\hline \multicolumn{3}{|c|}{ 䛔 } & $X_{d}(s)$ & $X_{Q}(s)$ \\
\hline (1) & & $|s|<\frac{1}{T_{d^{\prime}}}$ & $X_{d}$ & $X_{d}$ \\
\hline (2) & $\frac{1}{T d o^{\prime}}$ & $<|s|<\frac{1}{T_{d^{\prime}}}$. & $X_{d} \frac{\frac{1}{1+s T_{d^{\prime}}}}{1+s T_{d o^{\prime}}}$ & $X_{d}$ \\
\hline (3) & & $<|s|<\frac{1}{T_{90^{\circ}}}$ & $X_{d^{\prime}}\left(=X_{d} \frac{T_{d^{\prime}}}{T_{d 0^{\prime}}}\right)$ & $X_{d}$ \\
\hline (4) & $\frac{1}{T_{40}}$ & $<|s|<\frac{1}{T_{q}^{\prime \prime}}$ & $X_{d^{\prime}} \frac{1+s T_{d^{\prime \prime}}}{1+s T_{80^{\prime \prime}}}$ & $X_{d} \frac{1+s T_{d^{\prime}}}{1+s T_{d o^{\prime}}}$ \\
\hline (5) & $\frac{1}{T_{d^{*}}}$ & $<|s|<\frac{1}{T_{q 0} e^{\prime \prime}}$ & $X_{d^{\prime \prime}}\left(=X_{d^{\prime}} \frac{T_{d^{*}}}{T_{q 0^{\circ}}}\right)$ & $X_{d^{\prime \prime}}$ \\
\hline (6) & $\frac{1}{T_{q 0^{\text {III }}}}$ & $<|s|<\frac{1}{T_{q}^{m}}$ & $X_{d{ }^{\prime \prime}} \frac{1+s T_{q}{ }^{m}}{1+s T_{q 0^{m}}}$ & $X_{d^{*}} \frac{1+s T_{q}^{\prime \prime}}{1+s T_{q q^{\prime \prime}}}$ \\
\hline (7) & $\frac{1}{T_{q}^{\prime \prime \prime}}$ & & $X_{d^{m}}\left(=X_{d}{ }^{*} \frac{T_{q}{ }^{m}}{T_{q e^{m}}}\right)$ & $X_{d^{\prime \prime}}$ \\
\hline
\end{tabular}
$X_{s}(s)$ は表 1 のように $s$ 絶対值に応じて次数の低い 有理関数で近似することがでさる。従って，各々の場 合の $X_{d}(s), X_{q}(s)$ の近似式を(4)式に代入すると,

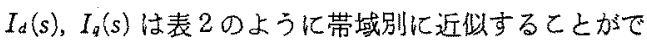
きる。その際, $r_{a} \ll X_{d}, X_{d}^{\prime}, X_{d}^{\prime \prime}, X_{d}^{\prime \prime \prime}$ と(7)式の 条件を用いた。

表 2 より, $T_{a}=X_{d}^{\prime \prime \prime} /\left(\omega_{0} r_{a}\right)$ と沶くと, $I_{d}(s)$ の極は $s=0,-1 / T_{d^{\prime}},-1 / T_{d}^{\prime \prime},-1 / T_{q}^{\prime \prime \prime},-1 / T_{a} \pm j \omega_{0}, I_{q}(s)$ の極は $s=0,-1 / T_{q}{ }^{\prime \prime},-1 / T_{q}^{\prime \prime \prime},-1 / T_{a} \pm j \omega_{0}$ である ことがわかる。(4)式の分母は八次式であるが，極の 数は $I_{d}(s), I_{q}(s)$ について各々 $6 ， 5$ 個である。これ

表 1 オペレーショナルインピーダンスの 帯域別有理関数近似式

Table 1. Approximate rational functions for operational impedances. 
表 $2 I_{d}(s), I_{q}(s)$ の帯域別有理関数近似式

Table 2. Approximate rational functions for $I_{d}(s)$ and $I_{q}(s)$.

\begin{tabular}{|c|c|c|}
\hline & $I_{d}(s)$ & $I_{\Delta}(s)$ \\
\hline (1) & $\frac{-V_{L}}{s X_{d}} \cos \delta$ & $\frac{-V_{L}}{s X_{d}} \sin \delta$ \\
\hline (2) & $\frac{-V_{L}}{s X_{d}} \frac{1+s T_{d o^{\prime}}}{1+s T_{d^{\prime}}} \cos \delta$ & $\frac{-V_{L}}{s X_{d}} \sin 8$ \\
\hline (3) & $\frac{-V_{L}}{s X_{d^{\prime}}} \cos 8$ & $\frac{-V_{L}}{s X_{d}} \sin 8$ \\
\hline (4) & $\frac{-V_{L}}{s X_{d^{\prime}}} \frac{1+s T_{40^{\prime \prime}}}{1+s T_{d^{\prime \prime}}} \cos \theta$ & $\frac{-V_{L}}{s X_{d}} \frac{1+s T_{Q a}}{1+s T_{q}} \sin \delta$ \\
\hline (5) & $\frac{-V_{L}}{s X_{d}} \cos \delta$ & $\frac{-V_{L}}{s X_{d^{\prime}}} \sin 8$ \\
\hline (6) & $\frac{-V_{L}}{s X_{d^{\prime}}} \frac{1+s T_{Q 0}}{1+s T_{Q}} \cos \delta$ & $\frac{-V_{L}}{s X_{d}^{*}} \frac{1+s T_{q 0^{*}}}{1+s T_{q}} \sin \delta$ \\
\hline (7) & $\begin{array}{l}\frac{-V_{L}}{s X_{d}}\left\{\left(\frac{s}{\omega_{0}}+\frac{r_{a}}{X_{d^{m}}}\right) \sin \delta\right. \\
+\cos \delta\} /\left\{\left(\frac{s}{\omega_{0}}+\frac{r_{a}}{X_{d^{m}}}\right)^{2}+1\right\}\end{array}$ & $\begin{array}{l}\frac{-V_{L}}{s X_{d}^{\prime \prime}}\left\{-\left(\frac{s}{\omega_{0}}+\frac{T_{a}}{X_{d^{m}}}\right) \cos \delta\right. \\
+\sin \delta\} /\left\{\left(\frac{s}{\omega_{0}}+\frac{r_{a}}{X_{d}}\right)^{2}+1\right\}\end{array}$ \\
\hline
\end{tabular}

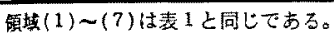

は, $I_{d}(s)$ については領域(4)で $s=-1 / T_{q}{ }^{n},(6)$ で $s=-1 / T_{q}{ }^{m \prime}$ が, $I_{q}(s)$ 飞ついては領域(2)で $s=$

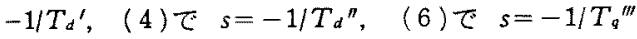
か，各々分母，分子に共通な根となっているからであ る。各々の極に対応する時間領域の解を，へビサイド

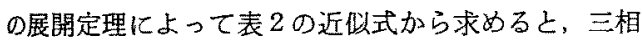
突発短絡時の電機子電流の変化分は次の上うになる。

$$
\begin{aligned}
i_{d}(t)= & I_{s}\left\{\left\{1+K_{d 1} \exp \left(-t / T_{d^{\prime}}\right)+K_{d 2}\right.\right. \\
& \left.\times \exp \left(-t / T_{d^{\prime \prime}}\right)+K_{q^{3}} \exp \left(-t / T_{q}^{\prime \prime \prime}\right)\right\} \\
& \left.\times \cos \delta-K_{q a} \exp \left(-t / T_{a}\right) \cos \left(\omega_{0} t+\delta\right)\right] \\
i_{q}(t)= & I_{s}\left(\left\{1+K_{q 2} \exp \left(-t / T_{q^{\prime \prime}}\right)+K_{q^{3}}\right.\right. \\
& \left.\times \exp \left(-t / T_{q}^{\prime \prime \prime}\right)\right\} \sin \delta-K_{q a} \\
& \left.\times \exp \left(-t / T_{a}\right) \sin \left(\omega_{0} t+\delta\right)\right\}
\end{aligned}
$$

とこで,

$$
I_{s}=-V_{L} / X_{d}
$$

とおいた。 $K_{d 1 \sim K_{q a}}$ は;

$$
\left.\begin{array}{l}
K_{d 1}=X_{d} / X_{d^{\prime}}-1, \quad K_{q 2}=X_{d} / X_{d}^{\prime \prime}-1 \\
K_{d 2}=X_{d} / X_{d}^{\prime \prime}-X_{d} / X_{d^{\prime}} \\
K_{q 3}=X_{d} / X_{d}^{\prime \prime \prime}-X_{d} / X_{d}^{\prime \prime}, \quad K_{q a}=X_{d} / X_{d}^{\prime \prime \prime}
\end{array}\right\}
$$

となる。（8)式は言い换元机ば, $I_{d}(s), I_{q}(s)$ は次式の ように近似するととができるということである。

$$
\left.\begin{array}{rl}
I_{d}(s)= & \frac{I_{s} \omega_{0}\left(1+s T_{d o^{\prime}}\right)\left(1+s T_{q o}{ }^{\prime \prime}\right)\left(1+s T_{q}{ }^{\prime \prime \prime}\right)}{s\left(1+s T_{d^{\prime}}\right)\left(1+s T_{d}{ }^{\prime \prime}\right)\left(1+s T_{q}^{\prime \prime \prime}\right)} \\
& \times \frac{\left\{\left(s+1 / T_{a}\right) \sin \delta+\omega_{0} \cos \delta\right\}}{\left\{\left(s+1 / T_{a}\right)^{2}+\omega_{0}{ }^{2}\right\}}
\end{array}\right\}
$$

$$
\begin{aligned}
I_{q}(s)= & \frac{I_{s} \omega_{0}\left(1+s T_{q o}{ }^{\prime \prime}\right)\left(1+s T_{q o^{\prime \prime \prime}}\right)}{s\left(1+s T_{q}^{\prime \prime}\right)\left(1+s T_{q}^{\prime \prime \prime}\right)} \\
& \times \frac{\left\{-\left(s+1 / T_{a}\right) \cos \delta+\omega_{0} \sin \delta\right\}}{\left\{\left(s+1 / T_{a}\right)^{2}+\omega_{0}{ }^{2}\right\}}
\end{aligned}
$$

以上から，電機子電流の過湾变化分仿従来機の結果 に，ダンパが二重であることを考虑して時定数 $T_{q}^{\prime \prime \prime}$ の減衰項を付け加えればよいことがわかる。全電機子 電流は，短絡前の負荷電流に（8)式を加えたものであ る。

〈3.2〉界磁電流の過渡变化 次化, 界磁電流の 変化分の近似解を求的る。電機子電流々界磁電流の関 保式は次のように与えられる。まず，界磁回路の電圧 方程式と鎖交磁束数の関保式は，

$$
\begin{aligned}
& E_{f d}(s)=s \Psi_{f}(s)+r_{f} I_{f}(s) \quad \ldots \ldots \ldots \ldots \ldots \\
& \Psi_{f}(s)=\sqrt{\frac{3}{2}} M_{a f 1}(s) I_{d}(s)+L_{f f 1}(s) I_{f}(s)
\end{aligned}
$$

である。ここで, $M_{a f 1}(s)$ は電機子巻線と界磁巻線の 相互インダクタンスの演算子形， $L_{f f 1}(s)$ は界磁巻線 の自己インダクタンスの演算子形である。(12)，(13) 式で $E_{f d}(s)=0$ [重衫合せの理，(3)式〕として $\Psi_{f d}(s)$ を消去すると

$$
\left.\begin{array}{l}
I_{f}(s)=-s G(s) I_{d}(s) / \omega_{0} \\
G(s)=\sqrt{\frac{3}{2}} \frac{\omega_{0} M_{a f 1}(s)}{r_{f}+s L_{f f 1}(s)}
\end{array}\right\}
$$

が成立する。

前節で $I_{d}(s)$ の近以式は求められているので， $G(s)$ の近似式を同様に考元ればよい。 $M_{a / 1}(s)$ は，付録の 記号を用いて，

$$
M_{a f 1}(s)=M_{a f 1}(0) / U_{1}(s)
$$

上表される。 $U_{1}(s)$ は表3のように $|s|$ に応じて近似 されるので(4),

$$
U_{1}(s)=\frac{\left(1+s T_{q 0}{ }^{\prime \prime}\right)\left(1+s T_{q} o^{\prime \prime \prime}\right)}{S_{c_{1}}(s) S_{c_{2}}(s)}
$$

と表すととができる。ここで，

$$
\left.\begin{array}{l}
S c_{k}(s)=\alpha_{k} d_{k} / \sinh \left(\alpha_{k} d_{k}\right) \\
\alpha_{k}=\sqrt{\mu_{0} \sigma_{k} s} \quad(k=1,2)
\end{array}\right\}
$$

とした。また, $L_{f f 1}(s)$ は，

$$
L_{f f 1}(s)=L_{f f 1}(0)\left(1+s T_{f}^{\prime \prime}\right) /\left(1+s T_{q o} o^{\prime \prime}\right)
$$

のように有理関数近似されるので(4),

$$
\begin{aligned}
& r_{f}+s L_{f f 1}(s) \\
& \quad=r_{f}\left(1+s T_{d o}{ }^{\prime}\right)\left(1+s T_{f}^{\prime \prime}\right) /\left(1+s T_{q 0^{\prime \prime}}\right)
\end{aligned}
$$


表 $3 \quad U_{1}(s)$ の帯域別近似表現式

Table 3. Approximate functions for $U_{1}(s)$.

\begin{tabular}{c|c|c|c|c}
\hline & $(1),(2),(3)$ & $(4)$ & $(5),(6)$ & $(7)$ \\
\hline$U_{3}(s)$ & 1 & $1+s T_{q 0^{*}}$ & $s T_{Q 0^{\circ}\left(1+s T_{\left.q 0^{\prime \prime}\right)} \frac{\sinh \left(\alpha_{1} d_{1}\right)}{\alpha_{3} d_{1}}\right.}$ & $s T_{q 0^{\prime \prime}} s T_{q 0^{\prime \prime}} \frac{\sinh \left(\alpha_{1} d_{1}\right)}{\alpha_{1} d_{1}} \frac{\sinh \left(\alpha_{2} d_{2}\right)}{\alpha_{2} d_{2}}$ \\
\hline
\end{tabular}

㙁域(1)〜(?)は表1の彷颣と同じである。

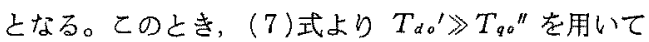
式を变形した。以上より， $I_{f}(s)$ は次式の上うに近似 することができる。

$$
\begin{aligned}
I_{f}(s)= & I_{f 0} K_{d 1} \frac{T_{d^{\prime}}\left(1+s T_{q o^{\prime \prime}}\right) S_{C_{2}}(s)}{\left(1+s T_{d^{\prime}}\right)\left(1+s T_{d^{\prime \prime}}\right)\left(1+s T_{f^{\prime \prime}}\right)} \\
& \times \frac{S_{C_{2}}(s)}{\left(1+s T_{q}{ }^{\prime \prime \prime}\right)} \frac{\left\{\left(s+1 / T_{a}\right) \sin \delta+\omega_{0} \cos \delta\right\}}{\left\{\left(s+1 / T_{a}\right)^{2}+\omega_{0}^{2}\right\}}
\end{aligned}
$$

ことで

$$
I_{f 0}=\sqrt{\frac{2}{3}} \frac{V_{L}}{\omega_{0} M_{a f 1}(0)}
$$

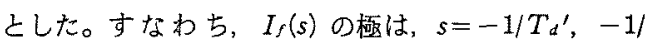
$T_{d}^{\prime \prime},-1 / T_{f^{\prime \prime}},-1 / T_{q}^{\prime \prime \prime},-1 / T_{a} \pm j \omega_{0}$ の 6 個亡 $\sinh$ $\left(\alpha_{k} d_{k}\right)=0(k=1,2)$ 上b，

$$
s=-\frac{m^{2} \pi^{2}}{\mu_{0} \sigma_{k} d_{k}^{2}}=-\frac{1}{\tau_{k m}}(m=1,2, \cdots) \ldots
$$

である。

各々に対忍する解を展開定理によって求めると，三 相突発短絡時の界磁電流の変化分は次の上うになる。

$$
\begin{aligned}
i_{f}(t) & =I_{f 0} K_{d 1}\left[\exp \left(-t / T_{d^{\prime}}\right)+K_{f 2}\right. \\
& \times \exp \left(-t / T_{d}^{\prime \prime}\right)-\left(1+K_{f 2}\right) \exp \left(-t / T_{f}^{\prime \prime}\right) \\
& \left.+K_{f 3} \exp \left(-t / T_{q}^{\prime \prime \prime}\right)\right\} \cos \delta+K_{f a} \\
& \times \exp \left(-t / T_{a}\right) \cos \left(\omega_{0} t+\delta\right) \\
& +\sum_{k=1}^{2} \sum_{m=1}^{\infty} K_{s c_{f m}} \exp \left(-t / \tau_{k m}\right) \\
& \left.\times \cos \left(\delta-\theta_{k m}\right)\right] \ldots \ldots \ldots \ldots \ldots \ldots \ldots \ldots \ldots \ldots \ldots \ldots
\end{aligned}
$$

上式の各係数㳉 (7)式の条件上表 3 を参照する之

$$
\begin{aligned}
& K_{f 2}=\frac{T_{q o}{ }^{\prime \prime}-T_{d} \prime}{T_{d}{ }^{\prime \prime}-T_{f^{\prime \prime}}} \\
& K_{f^{3}}=\frac{T_{q o^{\prime \prime}} T_{q}{ }^{\prime \prime \prime}}{T_{d^{\prime \prime}} T_{f^{\prime \prime}}} S_{c}\left(-1 / T_{q}{ }^{\prime \prime \prime}\right) \\
& K_{f a}=\frac{T_{q o} \prime \prime}{T_{d} \prime \prime} T_{f^{\prime \prime}} T_{q}^{\prime \prime \prime} \omega_{0}^{2} \\
& \times\left|S_{C_{1}}(s) S_{C_{2}}(s)\right| s=-\left(1 / T_{q}\right)+j \omega_{s} \\
& K_{s C_{f m}}=\frac{T_{q o^{\prime \prime}} \tau_{k m^{2}}{ }^{2}}{T_{d^{\prime \prime}} T_{f}{ }^{\prime \prime} T_{q}^{\prime \prime \prime}} \frac{2}{\cos (m \pi)} \frac{S_{c k}\left(-1 / \tau_{k m}\right)}{V} \\
& \tan \theta_{k m}=\left(1 / \tau_{k m}-1 / T_{a}\right) / \omega_{0}
\end{aligned}
$$

となる。(23)式加ら界磁電流については，従来知られ
ていない $T_{f}{ }^{\prime \prime}, \tau_{\mathrm{rm}}$ という時定数の減衰项が存在する ことがわかる。T゙”は界磁巻線と低温ダンパの相互 作用による時定数であり， $\tau_{k m}$ はダンパ円筒の厚みの 効果に上る時定数である。全界磁電流は短絡前の界磁 電流に（23）式を加えたものである。また，(23)式を時 間で微分すると界磁電流の時間変化率が得られる。時 間変化率は界磁巻線の常電導転移加らの保護を考える ときに必要となる。

〈3.3〉 ダンパ円筒の電流密度の過渡变化 次佂, 半径, 周方向の分布をもつダンパ円筒の電流密度の近 似解を求ぬる。電機子電流の $\xi$ 相成分とダンパ円筒の 電流密度の関係忹,

$$
\begin{array}{r}
I_{k}(r, \phi, s)=-\sigma_{k} s A_{\xi k}(r, \phi, s) \\
(\xi=a, b, c, k=1,2)
\end{array}
$$

と書ける。ここで, $A_{\xi k}(r, \psi, s)$ は二次元解析により,

$$
\begin{aligned}
A_{\xi k}(r, \psi, s)= & \sum_{n: \text { 奇 }} A_{k n}(r, s) I_{\xi}(s) \\
& \times \sin \{n p(\phi-2 m \pi / 3)\} \ldots
\end{aligned}
$$

と表さ机る ( $\xi=a, b, c$ に対して $m=0,1,2)$ 。乙こで，

$$
A_{1 n}(r, s)=c_{n} \alpha_{1} R_{1 i} O_{p, p+1}\left(\alpha_{1} r, \alpha_{1} R_{1 i}\right) / U_{1}(s)
$$

$$
\begin{aligned}
& A_{2 n}(r, s)=c_{n}\left(R_{2 i} / R_{2 o}\right)^{n p}\left(\alpha_{1} R_{1 i} \alpha_{1} R_{1 o} / 2 n p\right) \\
& \quad \times \alpha_{2} R_{2 i}\left\{O_{n p-1, n p+1}(1) O_{n p, n p+1}\right. \\
& \quad \times\left(\alpha_{2} r, \alpha_{2} R_{2 i}\right)-\left(R_{1 o} / R_{2 i}\right)^{2 n p} O_{n p+1, n p+1}(1) \\
& \left.\quad \times O_{n p, n p-1}\left(\alpha_{2} r, \alpha_{2} R_{2 i}\right)\right\} / U_{1}(s) \ldots \ldots(28)
\end{aligned}
$$

ただし，

$$
c_{n}=2 \mu_{0} N_{a} f_{a n} Y_{a n}\left(R_{1 i} / R_{a o}\right)^{n p} /\left\{n \pi\left(1-x_{a}^{2}\right)\right\}
$$

と与えられる(4)。(25)式で基本波成分のみ考慮して三 相分の和を取り $d-q$ 変换すると, 電機子電流 $d-q$ 成 分とダンパ円筒の電流密度の関係式として

$I_{k}(r, \phi, s)=I_{k d}(r, s) \sin (\not \phi)+I_{k q}(r, s) \cos (\phi \phi)$

を得る。ここで,

$$
\begin{aligned}
& {\left[\begin{array}{l}
I_{1 d}(r, s) \\
I_{1 q}(r, s)
\end{array}\right]=-\sqrt{\frac{3}{2}} \sigma_{1} s c_{1}} \\
& \quad \times \frac{\alpha_{1} R_{1 i} O_{p, p+1}\left(\alpha_{1} r, \alpha_{1} R_{1 i}\right)}{U_{1}(s)}\left[\begin{array}{l}
I_{d}(s) \\
I_{q}(s)
\end{array}\right] \\
& \ldots \ldots \ldots \ldots \ldots \ldots \ldots \ldots \ldots(30) \ldots \ldots \ldots \ldots \ldots \ldots \\
& {\left[\begin{array}{l}
I_{2 d}(r, s) \\
I_{2 q}(r, s)
\end{array}\right]=-\sqrt{\frac{3}{2}} \sigma_{2} s c_{1}\left(\alpha_{1} R_{1 i} \alpha_{1} R_{1 o} / 2 p\right)}
\end{aligned}
$$


表 4 変形ベッセル関数の近似表現式

Table 4. Approximations for modified Bessel functions.

\begin{tabular}{|c|c|c|c|c|}
\hline & (1) $\left|\alpha_{k} d_{k}\right| \ll<$ & (2) $\begin{array}{l}\left|\alpha_{k} d_{k}\right| \ll \\
1 \ll\left|\alpha_{k} R_{k}\right|\end{array}$ & (3) $1 \ll\left|\alpha_{k} R_{k}\right|$ & (4) $1<\left|\alpha_{k} d_{k}\right| \ll\left|\alpha_{k} R_{k}\right|$ \\
\hline$O_{n p+1, n p \pm 1}(k)$ & $\pm \frac{2 n p}{\alpha_{k} R_{k i} \alpha_{k} R_{k o}}$ & $\begin{array}{l}\frac{2 n p}{\alpha_{k} R_{k i} \alpha_{k} R_{k o}} \\
\quad \times\left( \pm 1+s T_{k n}\right)\end{array}$ & $\begin{array}{l}\frac{2 n p}{\alpha_{k} R_{k i} \alpha_{k} R_{k o}}\left\{ \pm \cosh \left(\alpha_{k} d_{k}\right)\right. \\
\left.+\frac{\alpha_{k} R_{k o}}{2 n p} \sinh \left(\alpha_{k} d_{k}\right)\right\}\end{array}$ & $\frac{\sinh \left(\alpha_{k} d_{k}\right)}{\alpha_{k} R_{k i}}$ \\
\hline $0_{n p \pm 1, n p \pm 1}(k)$ & 0 & $\frac{2 p s T_{k n}}{\alpha_{k} R_{k i} \alpha_{k} R_{k o}}$ & $\frac{\sinh \left(\alpha_{k} d_{k}\right)}{\alpha_{k} R_{k i}}$ & $\frac{\sinh \left(\alpha_{k} d_{k}\right)}{\alpha_{k} R_{k i}}$ \\
\hline $0_{n p, n p \neq 1}\left(\alpha_{k} r, \alpha_{k} R_{k i}\right)$ & \multicolumn{2}{|c|}{$\frac{1}{\alpha_{k} R_{k i}}\left(\frac{r}{R_{k i}}\right)^{n p}$} & $\begin{array}{l}\frac{1}{\alpha_{k} R_{k i}} \sqrt{\frac{R_{k i}}{r}}\left[\cosh \left\{\alpha_{k}\left(r-R_{k i}\right)\right\}\right. \\
\left. \pm \frac{n+ \pm(1 / 2)}{\alpha_{k} r} \sinh \left\{\alpha_{k}\left(r-R_{k i}\right)\right\}\right]\end{array}$ & $\frac{1}{\alpha_{k} R_{k i}} \sqrt{\frac{R_{k i}}{r}} \cosh \left\{\alpha_{k}\left(r-R_{k i}\right\}\right\}$ \\
\hline
\end{tabular}

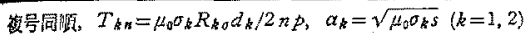

$$
\begin{aligned}
& \times \alpha_{2} R_{2 i}\left(R_{2 i} / R_{1 o}\right)^{p}\left\{O_{p-1, p+1}(1)\right. \\
& \times O_{p, p+1}\left(\alpha_{2} r, \alpha_{2} R_{2 i}\right)-\left(R_{1 o} / R_{2 i}\right)^{2 p} \\
& \left.\times O_{p+1, p+1}(1) O_{p, p-1}\left(\alpha_{2} r, \alpha_{2} R_{2 i}\right)\right\} \\
& \times\left[\begin{array}{c}
I_{d}(s) \\
I_{q}(s)
\end{array}\right] / U_{1}(s)
\end{aligned}
$$

$I_{k d}(r, s), I_{k q}(r, s)$ は各々電機子電流值軸, 横軸成分 によって生じるダンパ円筒電流密度のラプラス変換で あり, 各々 $p \phi=\pi / 2, p \phi=0$ におりる值を示す (因 1 参照)。界磁電流の場合と同様飞, $I_{k d}(r, s), I_{k q}(r, s)$ の近似式考荳ていく。まず, $O_{p, p \pm 1}\left(\alpha_{z} r, \alpha_{k} R_{k i}\right)$, $O_{p \pm 1, p \pm 1}(1)$ は表 $4^{(7)}$ のように近似されるので, 次式 のように表すことができる。

$$
\begin{aligned}
& O_{p, p \pm 1}\left(\alpha_{k} r, \alpha_{k} R_{k i}\right) \\
& =\frac{1}{\alpha_{k} R_{k i}}\left(\frac{r}{R_{k i}}\right)^{p} F_{k, p \pm 1}(r, s) \\
& F_{k, p \pm 1}(r, s)=\left(\frac{R_{k i}}{r}\right)^{p+1 / 2}\left[\cosh \left\{\alpha_{k}\left(r-R_{k i}\right)\right\}\right. \\
& \left.\quad \pm \frac{p \pm 1 / 2}{\alpha_{k} r} \sinh \left\{\alpha_{k}\left(r-R_{k i}\right)\right\}\right] \\
& O_{p-1, p+1}(1)=\frac{2 p}{\alpha_{1} R_{1 i} \alpha_{1} R_{10}} \frac{1+s T_{11}}{S_{c_{1}}(s)} \\
& O_{p+1, p+1}(1)=\frac{2 p}{\alpha_{1} R_{1 i} \alpha_{1} R_{10}} \frac{s T_{11}}{S_{c L}(s)}
\end{aligned}
$$

上式之， $I_{d}(s), I_{q}(s), U_{1}(s)$ の近似式 (11), (16)式を (30)，(31)式に代入する之， $I_{k d}(r, s), I_{k q}(r, s)$ の近似 式として次式が得られる。

$$
\begin{aligned}
& {\left[\begin{array}{c}
I_{1 d}(r, s) \\
I_{1 q}(r, s)
\end{array}\right]=I_{1 d} \frac{F_{1, p+1}(r, s)}{\left(1+s T_{q}^{\prime \prime \prime}\right)} S_{c_{1}}(s) S_{c_{2}}(s)} \\
& \quad \times\left[\begin{array}{c}
\frac{T_{q}^{\prime \prime}\left(1+s T_{d o^{\prime}}\right)}{\left(1+s T_{d}^{\prime}\right)\left(1+s T_{d^{\prime \prime}}\right)} \\
\frac{T_{q}^{\prime \prime}}{1+s T_{q}^{\prime \prime}}
\end{array}\right.
\end{aligned}
$$

電学論 D, 108 巻 11 号, 昭 63

$$
\left.* \begin{array}{c}
\frac{\left\{\left(s+1 / T_{a}\right) \sin \delta+\omega_{0} \cos \delta\right\}}{\left\{\left(s+1 / T_{a}\right)^{2}+\omega_{0}^{2}\right\}} \\
\frac{\left\{-\left(s+1 / T_{a}\right) \cos \delta+\omega_{0} \sin \delta\right\}}{\left\{\left(s+1 / T_{a}\right)^{2}+\omega_{0}^{2}\right\}}
\end{array}\right\}
$$

$$
\begin{aligned}
& {\left[\begin{array}{l}
I_{2 d}(r, s) \\
I_{2 q}(r, s)
\end{array}\right]=I_{2 d} \frac{T_{q}^{\prime \prime \prime}}{1+s T_{q}^{\prime \prime \prime}} S_{c_{2}}(s)} \\
& \quad \times\left\{\left(1+s T_{11}\right) F_{2, p+1}(r, s)\right. \\
& \left.-\left(\frac{R_{1 o}}{R_{2 i}}\right)^{2 p} s T_{11} F_{2, p-1}(r, s)\right\} \\
& \times\left[\begin{array}{c}
\frac{T_{q}^{\prime \prime}\left(1+s T_{d 0^{\prime}}\right)}{\left(1+s T_{d}^{\prime}\right)\left(1+s T_{d}^{\prime \prime}\right)} * \\
\frac{T_{q}^{\prime \prime}}{1+s T_{q}^{\prime \prime}} \\
\quad * \frac{\left\{\left(s+1 / T_{a}\right) \sin \delta+\omega_{0} \cos \delta\right\}}{\left\{\left(s+1 / T_{a}\right)^{2}+\omega_{0}^{2}\right\}} \\
\frac{\left\{-\left(s+1 / T_{a}\right) \cos \delta+\omega_{0} \sin \delta\right\}}{\left\{\left(s+1 / T_{a}\right)^{2}+\omega_{0}^{2}\right\}}
\end{array}\right]
\end{aligned}
$$

こで

$$
\left.\begin{array}{l}
I_{1 d}=\sqrt{\frac{3}{2}} \sigma_{1} c_{1}\left(\frac{r}{R_{1 i}}\right)^{p} \frac{V_{L}}{X_{d} T_{q} \prime} \\
I_{2 d}^{\prime}=\sqrt{\frac{3}{2} \sigma_{2} c_{1}\left(\frac{r}{R_{10}}\right)^{p} \frac{V_{L}}{X_{d} T_{q}^{\prime \prime}}}
\end{array}\right\}
$$

とした。これらに対応する解を求めると

$$
\begin{aligned}
i_{k}(r, \phi, t)= & i_{k d}(r, t) \sin (p \phi) \\
& +i_{k q}(r, t) \cos (p \phi)
\end{aligned}
$$

となる。とこで,

$$
\begin{aligned}
& i_{1 d}(r, t)=I_{1 d}\left\{\left\{-K_{d 1} T_{q}^{\prime \prime} / T_{d^{\prime}} \exp \left(-t / T_{d}^{\prime}\right)\right.\right. \\
& \left.\quad+\exp \left(-t / T_{d}^{\prime \prime}\right)-K_{13} \exp \left(-t / T_{q}^{\prime \prime \prime}\right)\right\} \cos \delta \\
& \quad-K_{1 a} \exp \left(-t / T_{a}\right) \cos \left(\omega_{0} t+\delta+\theta_{1 a}\right) \\
& \left.\quad+\sum_{k=1}^{2} \sum_{m=1}^{\infty} K_{S C_{1 m}} \exp \left(-t / \tau_{k m}\right) \cos \left(\delta-\theta_{k m}\right)\right)
\end{aligned}
$$




$$
\begin{aligned}
& i_{1 q}(r, t)=I_{1 d}\left[\left\{\exp \left(-t / T_{q}{ }^{\prime \prime}\right)\right.\right. \\
& \left.\quad-K_{13} \exp \left(-t / T_{q}{ }^{\prime \prime \prime}\right)\right\} \sin \delta-K_{1 a} \\
& \quad \times \exp \left(-t / T_{a}\right) \sin \left(\omega_{0} t+\delta+\theta_{1 a}\right) \\
& \left.\quad+\sum_{k=1}^{2} \sum_{m=1}^{\infty} K_{S C_{1 m}} \exp \left(-t / \tau_{k m}\right) \sin \left(\delta-\theta_{k m}\right)\right\}
\end{aligned}
$$

$$
\begin{aligned}
i_{2 d}(r, t) & =I_{2 d}\left[\left\{-K_{d 1} T_{q}^{\prime \prime \prime} \exp \left(-t / T_{d^{\prime}}\right) / T_{d^{\prime}}\right.\right. \\
& +T_{q}{ }^{\prime \prime \prime} / T_{q}^{\prime \prime} K_{22} \exp \left(-t / T_{d^{\prime \prime}}\right) \\
& \left.+K_{23} \exp \left(-t / T_{q}^{\prime \prime \prime}\right)\right\} \cos \delta \\
& -K_{2 a} \exp \left(-t / T_{a}\right) \cos \left(\omega_{0} t+\delta+\theta_{2 a}\right) \\
& \left.+\sum_{m=1}^{\infty} K_{S C_{2 m}} \exp \left(-t / \tau_{m 2}\right) \cos \left(\delta-\theta_{2 m}\right)\right]
\end{aligned}
$$

$$
\begin{aligned}
i_{2 q}(r, t) & =I_{2 d}\left[\left\{\left(T_{q}^{\prime \prime \prime} / T_{q}{ }^{\prime \prime}\right) K_{22} \exp \left(-t / T_{q}^{\prime \prime}\right)\right.\right. \\
& \left.-K_{23} \exp \left(-t / T_{q}{ }^{\prime \prime \prime}\right)\right\} \sin \delta \\
& -K_{2 a} \exp \left(-t / T_{a}\right) \sin \left(\omega_{0} t+\delta+\theta_{2 a}\right) \\
+ & \left.\sum_{m=1}^{\infty} K_{S C_{2 m}} \exp \left(-t / \tau_{2 m}\right) \sin \left(\delta-\theta_{2 m}\right)\right]
\end{aligned}
$$

\begin{tabular}{|c|c|c|c|}
\hline 定格容咀 & $1,120 \mathrm{MVA}$ & 定格䉓死 & $26 \mathrm{kV}$ \\
\hline $\begin{array}{l}\text { 極数 } \\
\text { 界磁卷線 }\end{array}$ & 2 & $\begin{array}{l}\text { 回 䡆 } \\
\text { 数璣子巻線 }\end{array}$ & $3,000 \mathrm{rpm}$ \\
\hline 内 径 & $0.59 \mathrm{~m}$ & 内 径 & $1.23 \mathrm{~m}$ \\
\hline $\begin{array}{c}\text { 外 径 } \\
\text { 低温舛ン゙ }\end{array}$ & $0.75 \mathrm{~m}$ & $\begin{array}{c}\text { 外徍 } \\
\text { 常温ダンパ }\end{array}$ & $1.62 \mathrm{~m}$ \\
\hline 愿 さ & $0.01 \mathrm{~m}$ & 厚 さ & $0.01 \mathrm{~m}$ \\
\hline 外 盈 & $0.82 \mathrm{~m}$ & 外 径 & $1.00 \mathrm{~m}$ \\
\hline 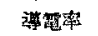 & 5. $0 \times 10^{8} \mathrm{~S} / \mathrm{m}$ & 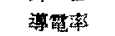 & $5.0 \times 10^{7} \mathrm{~S} / \mathrm{m}$ \\
\hline \multicolumn{4}{|c|}{ 外部機硪シーールド(鉄) } \\
\hline 内 径 & $1.69 \mathrm{~m}$ & & \\
\hline
\end{tabular}

であり，各係数は $(7)$ 式，表 $3 ，$ 表 4 を参照すると， 次式で与えられる。

$$
\begin{aligned}
K_{13}= & F_{1, p+1}\left(r,-1 / T_{q}{ }^{\prime \prime \prime}\right) S_{c_{1}}\left(-1 / T_{q}{ }^{\prime \prime \prime}\right) \\
K_{1 a} & \exp \left(j \theta_{1 a}\right)=\mid F_{1, p+1}(r, s) \\
& \times S_{c_{1}}(s) S_{c_{2}}(s) \mid s=-1 / T_{a}+j \omega_{o} \\
K_{S C_{1 m}}= & \frac{\tau_{1 m}}{T_{q}^{\prime \prime \prime}} \frac{2}{\cos (m \pi)} F_{1, p+1}\left(r,-1 / \tau_{k m}\right) \\
& \times \frac{S_{c_{2}}\left(-1 / \tau_{1 m}\right)}{V 1+\tan ^{2} \theta_{k m}} \\
K_{22}= & 1-\left(T_{11} / T_{d}^{\prime \prime}\right)\left\{1-\left(R_{1 o} / r\right)^{2 p}\right\} \\
K_{23}= & \left(T_{11} / T_{q}^{\prime \prime}\right)\left\{1-\left(R_{1 o} / r\right)^{2 p}\right\}
\end{aligned}
$$

表 51 GVA 級超電導発電機の

軖造パラメータの例

Table 5. Structure-parameter for 1GVA superconducting generator.

$$
\begin{aligned}
& K_{2 a} \exp \left(j \theta_{2 a}\right)=\left(T_{11} / T_{q}^{\prime \prime}\right) \mid S_{C_{2}}(s) \\
& \times\left\{F_{2, p+1}(r, s)\right. \\
&\left.-\left(\frac{R_{10}}{R_{2 i}}\right)^{2 p} F_{2, p-1}(r, s)\right\}\left.\right|_{S=-1 / T_{a}+j \omega_{0}} \\
& K_{S C_{2 m}}=\frac{T_{11}}{T_{q} m} \frac{2}{\cos (m \pi)} \mid F_{2, p+1}(r, s) \\
& \quad-\left.\left(\frac{R_{1 o}}{R_{2 i}}\right)^{2 p} F_{2, p-1}(r, s)\right|_{S=-1 / T_{a}+j \omega_{0}}
\end{aligned}
$$

である。(37)〜 (40)式から，ダンパ円筒の電流密度も 界磁電流之同様の, 種々の時定数の減衰項と減衰振動 項から成ることがわかる。

\section{4. 数 值 例}

近似解析解の精度を確かめるために，表5亿与え たような構造パラメータをむつ超電導発電㙨を考え る(3)。とのような $1 \mathrm{GVA}$ 䄲の超電導発電機が定格電
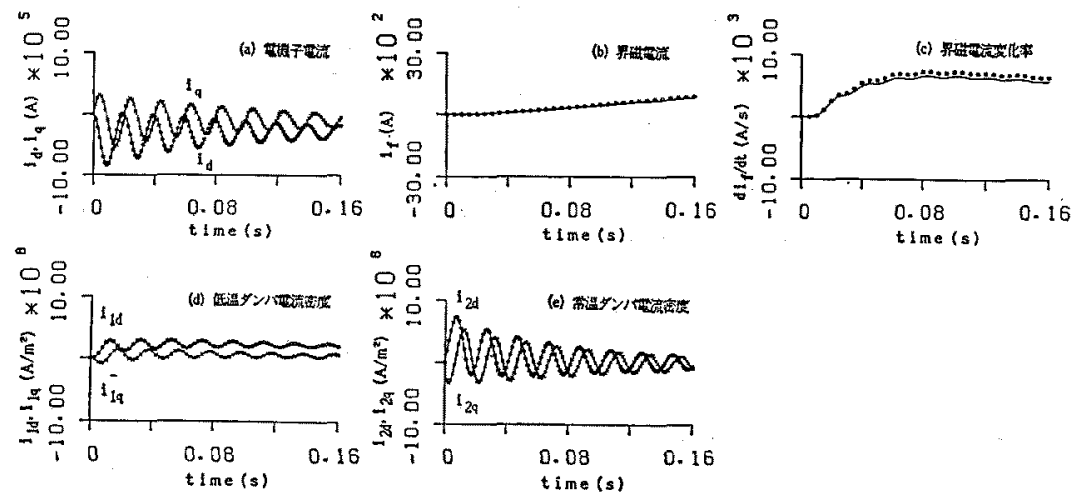

음

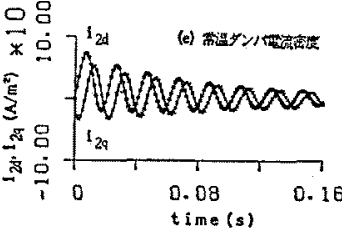

一: 数値解， $\mathrm{O}, \mathrm{x}$ : 近似解析解

図 2 三相突発短絡時の超電導発電機の過瀉電流

Fig. 2. Transient current of superconducting generator at sudden 3-phase short circuit. 
任，定格電流，力率 $0.9\left(\delta=18.1^{5}\right)$ ○状態加ら，発電 端子で $t=0$ において三相突発短絡を起こした場合 について，前章の近似式 (8)，(23)，(37)〜 (40)式によ 万破形と，变形べッセ儿関数定含む理論式(4)，(14)， (30)，(31)式加ら数值逆ラプラス变換 ${ }^{(8)}$ により計算し た波形を比較したのが図2である。同図に柾いて，䒠 楾か数值解，○，×印が近似解を各々表す。また，低 温ダンパ，常温ダンパの電流密度は，各々外側の表面 $\left(r=R_{\mathrm{l} s}, R_{20}\right)$ の6のである。また近似解では，時定 数 $\mathrm{k}_{\mathrm{m}}$ 代対応する減衰項は， $k=1$ では $m=3$ 主で, $k=2$ では $m=1$ のみを考虑した。

電機子䉓流，界醇電流，界磁電流落化率，ダンパ円 筒の電流密度の各々について, 近以解析解は数值逆亏 ナラス変換による結果上よく一致して衫り，近以計算 式の精度加高いことが確加らられた。

\section{5. 構造パラメータと解の関係}

第3章で得られた解析解によって構造パラメータ上 蟹の開係老考察する。

〈5.1) 電機子電流

(8)式を見ると，電機子電 流 $d, q$ 成分の過渡変化は従来機の場合 ${ }^{(7)}$ 上同様に,

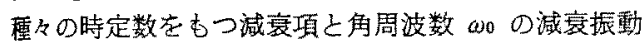
成分の和である。超電導機では二重ダッバ構造のだ に $T_{\mathrm{q}}{ }^{\prime \prime \prime}$ という常温ダンパ代起因する時定数の減衰項 加存在する。それらの項の初期値の相対值である $K_{d 1}$ $\sim K_{\mathrm{qa}}$ は，(10)式からわ加るように同期りアクタンス と過度りアクタンスの此によって決まる。同期リアク タンスと過渡り丁クタンスの比 $X_{d} / X_{d^{\prime}}, X_{d} / X_{d}{ }^{\prime \prime}$, $X_{d} / X_{A}{ }^{\prime \prime \prime}$ 洁各々電機子巻線上界磁巻線, 低温ダンパ, 常温ダンバの外径の比によって決まり,ダンパの導電

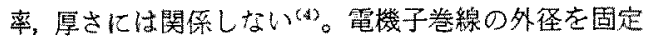
して具体的江考えると次の上うになる。界磁卷線の外

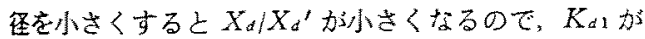
小さく $K_{\alpha 2}$ が大きくなる。低温ダンパの外径を小さ 〈すると $X_{d} / X_{d} "$ が小さくなるので, $K_{d 2}, K_{\text {; } 2}$ 方小 さく $K_{q 3}$ が大きくなる。常温ダンパの外经を小さくす ると， $X_{d} / X_{d}^{\prime \prime \prime}$ が小さくなるので, $K_{q 3}, K_{q a}$ 多小さ 〈なる。大体の目安しして、 $x_{a}=x_{f}=R_{a o} / R_{3 i}=0.8$, $\lambda_{a f} f^{2}\left(\lambda_{a} \lambda_{f}\right)=0.8$ 亡する之, 二極機の㫤合 $0.40<R_{f} d$ $R_{a \circ}<0.60, \quad 0.45<R_{10} / R_{00}<0.65, \quad 0.55<R_{2 o} / R_{0 \circ}<$ 0.75 飞対して, $0.26<K_{d 1}<0.71,0.29<K_{d 2}<1.45$, $0.54<K_{q 2}<1.89, \quad 0.44<K_{q 3}<2.45, \quad 1.99<K_{q a}<$ 5.33 之なる。前章の数值例では， $K_{a 1}=0.39, K_{d 2}$ $=0.54, K_{q 2}=0.93, K_{q 3}=0.98, K_{q 2}=2.91$ である。

無負荷加ら三相突発短絡加生じた場合 $(\delta=0),(8)$ 式を $d-q$ 逆变換し相電流を求めると， $a$ 相電流は,

$$
\begin{aligned}
i_{a}(t)= & \sqrt{\frac{2}{3}} I_{s}\left\{\left\{1+K_{d 1} \exp \left(-t / T_{d^{\prime}}\right)\right.\right. \\
& +K_{d 2} \exp \left(-t / T_{d^{\prime \prime}}\right)+K_{q 3} \\
& \left.\times \exp \left(-t / T_{q}{ }^{\prime \prime}\right)\right\} \cos \left(\omega_{0} t+\phi_{0}\right) \\
& \left.-K_{q a} \exp \left(-t / T_{a}\right) \cos \phi_{0}\right\} \ldots . .
\end{aligned}
$$

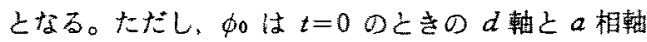
の間の電気角であり， $b, c$ 相電流は上式で $\phi_{0}$ を各々 $\phi_{0}-2 \pi / 3, \phi_{0}+2 \pi / 3$ で置き換えたものである。従つ

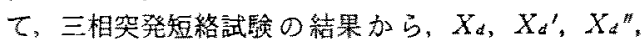
$X_{a}^{\prime \prime \prime}, T_{d^{\prime}}, T_{d}{ }^{\prime \prime}, T_{q}^{\prime \prime \prime}$ の值を求めることができる(9)。 ただし，試験では通常定格電生よりかなり低い電壬か ら短絡するので，ブラシの定電王降下の影㵱により测 定時の界磁回路抵抗分 $r$, が定格運䎐時上り大きくな る。従って，r $r_{f}$ に反比例する(4) $T_{d}^{s}$ の测定值は, 定 格運転時の值上り小さくなる。

また，(42)式より $i_{0}(t)$ の最大值は次式となる。

$$
\max \left|i_{a}(t)\right| \cong 2 \sqrt{\frac{2}{3}} \frac{V_{L}}{X_{d}{ }^{\prime \prime \prime}}
$$

〈5.2〉界磁電流従来機で结，三相突発短絡時 の界磁電流の変化は時定数 $T_{d}^{\prime}, T_{a}{ }^{\prime \prime}$ の減衰項之時定 数 $T_{0}$, 角周波数 $\omega_{0} 0$ の減衰振動項からなるが(6), 超電 導発雪機では(23)式よりこれらの項のほかに眭定数 $T_{f}^{\prime \prime}, \tau_{k m}(k=1,2, m=1,2, \cdots)$ の減衰項方存在方るこ とがわかる。こ机らの項の相対的な大きさについて考 える。まず， $K_{I 2}$ は(24)式加方各巻線，ダンパ円筒の 位置関係に上って決まると考元られる。前節之同じ条 件で $R_{f o} / R_{1 i}=0.9$ として計算すると， $0.36<K_{f 2}<$ 1.38 上なる。また, 前章の数值例では $K_{r 2}=0.54$ で ある。 $K_{f 3}, K_{f a}, K S C_{f m}$ に対しては，(24)式よりダ ンパ円筒の導電率と厚さの影暗が大きい。だいたいの 目安として $d_{1}=d_{2}=0.01 \mathrm{~m}, \sigma_{1}=5 \times 10^{8} \mathrm{~S} / \mathrm{m}$ (銅, 77 $\mathrm{K}), \sigma_{2}=5 \times 10^{7} \mathrm{~S} / \mathrm{m}\left(\right.$ (鉰, $\left.20^{\circ} \mathrm{C}\right)$ 亡すると, $\tau_{1 m}=6.37$ $\times 10^{-3} \mathrm{~s} \tau 2 \mathrm{~m}=6.37 \times 10^{-4} \mathrm{~s}$ 好ので, 時定数 $\tau_{\mathrm{m}}$ の減 衰項は $t=0$ の近傍以外では無視できる。またこのと き, $\left|\alpha_{1} d_{1}\right|=4.44,\left|\alpha_{2} d_{2}\right|=1.40$ であり, 加つ(7) 式上り $\omega_{0} T_{q}^{\prime \prime \prime} \gg 1, \omega_{0} T_{q}^{\prime \prime \prime} \gg 1$ 近考元ら机るので $K_{\text {。 }} \ll 1$ で古る。すなわち、ダンパ円筒の材質が銅で 卓さが $1 \mathrm{~cm}$ 程度であれば，界磁電流の変化分では時 定数 $\tau_{\mathrm{z} m}$ の減衰項之角周波数 $\omega_{0}$ の減衰振動項は小さ $<$, 封定数 $T_{d}^{\prime}, T_{d}^{\prime \prime}, T_{f}^{n}, T_{q}^{\prime \prime \prime}$ の減衰项に比へて 無視できる。同様の考察に上り, 界磁電流の時間変化

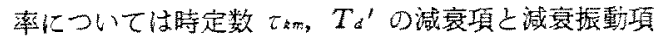
は小さい。

〈5.3〉 ダンパ円筒の電流密度 ダンパ円筒の電 流密度について子種々の時定数の減衰项之減衰振動項 加存在京るが，(7)式より $T_{a}^{\prime} \gg T_{q}^{\prime \prime} \gg T_{q}^{\prime \prime \prime}$ なので, (37)式の $i_{1 d}(r, t)$ の第 1 項は第 2 項に比心て小さく, (38)式の $i_{2 d}(r, t)$ の第 1,2 項上 $i_{2 q}(r, t)$ の第 1 項は 他の項に比へて小さい。高な放ち，低温ダンバ電流密 度については時定数 $T_{a}{ }^{\prime}$ の減衰项は小さく，時定数

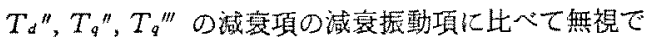
きる。特に $\delta$ 功さい状態加らの短絡の場合は $\sin \delta$

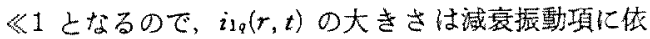
存することになる。また，常温ダンバ電流密度につい ては，時定数 $T_{d}^{\prime} ， T_{d}^{\prime \prime}, T_{q}{ }^{\prime \prime}$ の減亮项は小さく, 時 定数 $T_{9}{ }^{\prime \prime \prime}$ の減言項之角周波数 $\omega_{0}$ の減哀振勂項に比 
ベて無視できる。また，時定数 $\tau_{\mathrm{km}}$ の減衰項は界磁電 流の場合と同様に，ダンパ円筒の電流密度においても $t=0$ の近傍以外では無視できる。

\section{6.むすび}

二次元電磁界解析の結果によると, 超電導発電機の 三相突発短絡電流の過渡変化分のラプラス变換は，理 諭的に変形ベッセル関数を含むが，オペレーショナル インピーダンスに有理関数近似式を用いることにより 有理関数で近似できる。本論文では，てのような電磁 界解析の結果を用いた放密な議論により, 解析的にう プラス变換の極が求らることを示した。そして, 実際にへビサイドの展開定理を適用し，時間領域の近 似解を解析的に求めた。界磁電流，ダンパ円筒電流密 度の過渡变化分についても同様に解析解を得た。得ら れた近做解加ら以下のととが竞える。

（1）電機子電流については，従来機で得られてい る結果に時定数 $T_{q}^{\prime \prime \prime}$ の娍衰項を付け加えればよい。

(2)。界磁電流については，従来知られていない時 定数の減裳項が存在する。

（3）ダンパ円筒の電流密度については，こ机まで 導出さ机ていなかった半径方向, 周方向の分布を考慮 した式か得られた。

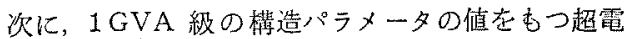
導発電機について解析解上数值逆ラプラス変換による 数值解を比較した結果, 両者はよく一致した。従っ

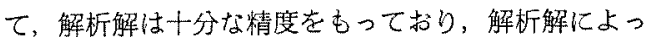
てダンパ円筒に働く過渡的なトルク，半径方向応力な どを評価することができる。

解析解はパラメータとして各種のリアクタンス，時 定数を含んでいるが，それらはすべて発電機の橗造パ ラメータの簡単な関数として与えられている(4)。従っ て, 過渡特性上蹢造パラメータの関係の把握が容易て ある。解析解によって, 電機子電流, 界磁電流, ダン パ円筒電流密度の過渡变化分が電機子巻線, 界磁巻 線，低温ダンパ，常温ダンパの外径の比などの棈造パ ラメータの関保を検討した。

なお，本論文中の数值計算は一部文部省科学研究費 補助金（エネルギー特別研究）の援助によって行われ た。最後に，数值逆ラプラス变換について御教示いた だいた京都大学工学部 市川 哲助手に感謝します。

(昭和 63 年 3 月 25 日受付, 同 63 年 9 月 2 日再受付)

\section{文献}

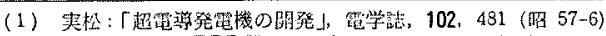

(2) J. L. Smith: IEEE Trans. Magnetics, MAG-19, 552 (1983)

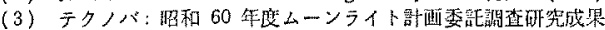

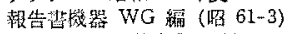

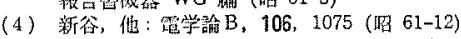

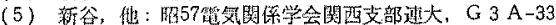

(6) 斯谷, 他: 笛気学会篦力技研資, PE-86-58 (昭 61-8)

(7) B. Adkins: The General Theory of Electrical Machines, p. 101 (1964) Chapman \& Hall Ltd.

(8) S. Ichikawa, et al. : Memoiors of Faculty of Eng. Kyoto Univ, 34, 53 (1972-1)

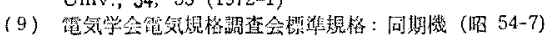

\section{付 録}

\section{記 号}

$A=(0,0, A):$ ベクトルポテンシャル $(\mathrm{Wb} / \mathrm{m}), \Psi:$ 銷交磁束数 $(\mathrm{Wb} /$ 回数 $), L, M$ : 各々目己, 相互イン ダクタンス $(\mathrm{H}), X$ : リアクタンス $(\Omega), p$ : 極対数, $N:$ 一極あたり導体数, $d:$ ダンパの厚さ $(\mathrm{m}), R$ : 半 径 $(\mathrm{m}), \mu_{0}$ : 真空の透磁率 $(\mathrm{H} / \mathrm{m}), \sigma:$ 導電率 $(\mathrm{S} / \mathrm{m})$, $\phi, \psi$ : 各色 $d$ 軸, $a$ 相軸加らの機械角 $(\mathrm{rad}), \theta:$ 巻 線の占內る角度（機械角）( $\mathrm{rad}), \omega$ : 角周波数（電気 角) $(\mathrm{rad} / \mathrm{s}) ， \omega_{0}$ ：同期角周波数 (電気角) $(\mathrm{rad} / \mathrm{s}), \lambda:$ 巻 線の軸方向有效長 $(\mathrm{m}), S$ : 滑り

(添字) $a, b, c$ : 電機子各相, $d$ : 直軸, $q$ : 横軸, $f:$ 界磁, $1:$ 低温ダンパ, $2:$ 常温ダンパ, $3:$ 外部シ 一ルド, $i:$ 内半径, $o:$ 外半径, $n:$ 空間高調波次数

(i) 巻線分有関するむの

$$
f_{\xi n}=\sin \left(n p \theta_{\xi} / 2\right) /\left(n p \theta_{\xi} / 2\right) \text {. }
$$

(ii) 半径の比関するあの

$$
\begin{aligned}
x_{\xi}= & R_{\xi} / R_{\xi o} \\
y_{n}(x) & =\left(1-x^{n p+2}\right) /(n p+2) \\
Y_{\xi n}=y-n\left(x_{\xi}\right) \pm\left(R_{\xi o} / R_{3 i}\right)^{2 n_{p}} y_{n}\left(x_{\xi}\right) & \\
Z_{\xi n}= & \left\{y_{n}\left(x_{\xi}\right)-y-n\left(x_{\xi}\right) x_{\xi}^{n p+2}\right\} / 2 \\
& \pm\left(R_{\xi} / R_{3 i}\right)^{2 n p} y_{n}{ }^{2}\left(x_{\xi}\right)
\end{aligned}
$$

ただし $, \xi=a, f$ であり, $-n p+2=0$ のとき

$$
y-n\left(x_{\xi}\right)=-\ln x_{\xi}
$$

である。

(iii) 变形ベッセル関数に関するもの

$$
\begin{aligned}
O_{u, v}(z, w)= & I_{u}(z) K_{v}(w) \\
& -(-1)^{u-v} K_{u}(z) I_{v}(w)
\end{aligned}
$$

これを更に略して

$$
\begin{aligned}
O_{v, v}(k)= & I_{u}\left(\alpha_{k} R_{k o}\right) K_{v}\left(\alpha_{k} R_{k i}\right) \\
& -(-1)^{u-v} K_{u}\left(\alpha_{k} R_{k o}\right) I_{v}\left(\alpha_{k} R_{k i}\right)
\end{aligned}
$$

ただし， $\alpha_{k}=\sqrt{\mu 0 \sigma_{k} s}(k=1,2)$ である。

$O_{u, v}(k)(k=1,2)$ を用いて,

$$
\begin{aligned}
U_{n}(s)= & \frac{\alpha_{1} R_{1 i} \alpha_{1} R_{10}}{2 n p} \frac{\alpha_{2} R_{2 i} \alpha_{2} R_{2 o}}{2 n p}\left(\frac{R_{1 i} R_{2 i}}{R_{10} R_{2 o}}\right)^{n p} \\
& \times\left(O _ { n p - 1 , n p + 1 } ( 1 ) \left\{O_{n p-1, n p+1}(2)\right.\right. \\
& \left. \pm\left(R_{2 o} / R_{3 i}\right)^{2 n_{p}} O_{n p+1, n p+1}(2)\right\} \\
& -\left(R_{10} / R_{2 i}\right)^{2 n p} O_{n p+1, n p+1}(1) \\
& \times\left\{O_{n p-1, n p-1}(2) \pm\left(R_{2 o} / R_{3 i}\right)^{2 n p}\right. \\
& \left.\left.\times O_{n p+1, n p-1}(2)\right\}\right] \ldots \ldots \ldots \ldots(\text { 付 } 4)
\end{aligned}
$$

(iv）インダクタンスに関するもの

$$
\begin{aligned}
L_{\xi \xi 1}(0)= & \frac{8 \mu_{0} \lambda_{\xi}}{p \pi}\left(f_{\xi 1} \frac{p N_{\xi}}{1-x_{\xi}^{2}}\right)^{2} Z_{\xi 1} \quad(\xi=a, f) \\
M_{a f 1}(0)= & \frac{8 \mu_{0} \lambda_{a f}}{p \pi} f_{a 1} \frac{p N_{a}}{1-x_{a}^{2}} f_{f 1} \frac{p N_{f}}{1-x_{f}^{2}} \\
& \times Y_{a 1} y_{1}\left(x_{f}\right)\left(\frac{R_{f o}}{R_{a o}}\right)^{p} \ldots \ldots \text { (付 } 5 \text { ) }
\end{aligned}
$$

